\title{
¿Buscar el bienestar de la ciudad, o marcharse mientras ella se quema? Lectura política e intertextual de Jr 29 y Lc 17 en relación con las crisis migratorias del siglo $\mathrm{XXI}^{*}$
}

\author{
Christopher Michael Hays ${ }^{\mathrm{a}}$ \\ Fundación Universitaria Seminario Bíblico de Colombia \\ http://orcid.org/0000-0001-5050-4918
}

RECIBIDO: 02-12-2019. APROBADO: 08-09-2020

Resumen: Este artículo fusiona la exégesis crítica con la reflexión sociopolítica para mostrar cómo una tensión desafiante en las Escrituras puede nutrir respuestas matizadas a crisis sociales. $\mathrm{Al}$ comenzar con un estudio intertextual, se identifica que Lc 17,27-28 hace alusión y subvierte a Jr 29,5-7. Se nota que las actividades que Jr 29 encomienda a los exiliados en Babilonia (plantar, edificar, casar y dar en casamiento) son las mismas actividades criticadas por Lc 17, y que hay otras similitudes entre Lc 17 y Jr 32 y 35, todo lo cual revela que Lucas pretende contrastar la situación de su audiencia con la de los exiliados en Babilonia, y propone así una ética distinta para los discípulos de su época. Aunque el profeta animó a sus lectores exiliados a entregarse al desarrollo económico y familiar en Babilonia, el evangelista advierte en contra de preocupaciones mundanas que estorban su compromiso con el Reino. Se propone que esta tensión intracanónica facilita un acercamiento diferenciado a dos crisis migratorias actuales, aplicando la perspectiva de Jeremías para animar a las víctimas del desplazamiento forzoso en Colombia a echar raíces en sus sitios de llegada, y recurriendo a Lc 17 para criticar la deportación estadounidense de los migrantes indocumentados. Se justifica este acercamiento hermenéutico diferenciado por medio de un estudio de la actividad redaccional de Lucas (transformando las enseñanzas de Mt 24 y Mc 13 sobre el evento de la parusía a exhortaciones sobre cómo vivir de manera ética antes de la parusía) y de la polifonía ética de Jeremías (la cual se nota en los divergentes estilos de vida afirmados por Jr 16,2-4; 29,6; 35,6-7). Se argumenta que esta moralidad multifacética cuadra con una visión neotestamentaria equilibrada que caracteriza a los cristianos como exiliados y a la vez ciudadanos (Hb 11,13-14; 1P 2,1).

Palabras Clave: Lucas; Jeremías; ética bíblica; interpretación política; crítica de la redacción; intertextualidad; desplazamiento forzoso; migración.

\footnotetext{
*Artículo de investigación.

${ }^{a}$ Autor de correspondencia. Correo electrónico: cmhays@gmail.com. Profesor titular de Nuevo Testamento, Fundación Universitaria Seminario Bíblico de Colombia. Investigador internacional asociado del Departamento de Nuevo Testamento, de la Facultad de Teología de la Universidad de Pretoria.
} 
Seek the Welfare of the City or Walk Away as it Burns? A Political and Intertextual Reading of Jer 29 and Lk 17 in Relation to the Migratory Crises of the 21st Century

Aвsтract: This article fuses critical exegesis with socio-political reflection to show how a challenging tension in Scripture can nurture nuanced responses to social crises. Beginning with an intertextual study, it is identified that $\mathrm{Lk}$ 17:27-28 alludes to and subverts Jer 29:5-7. It is noted that the activities that Jer 29 entrusts to the exiles in Babylon (planting, building, marrying and giving in marriage) are the same activities criticized by Lk 17, and that there are other similarities between Lk 17 and Jer 32 and 35, all of which reveals that Luke intends to contrast the situation of his audience with that of the exiles in Babylon, and thus proposes a different ethic for the disciples of his time. Although the prophet encouraged his exiled readers to devote themselves to economic and family development in Babylon, the evangelist warns against worldly concerns that hinder their commitment to the Kingdom. The author proposes that this intracanonical tension facilitates a differentiated approach to two current migratory crises, applying Jeremiah's perspective to encourage the victims of forced displacement in Colombia to put down roots in their places of arrival, and using Lk 17 to criticize the U.S. deportation of undocumented migrants. This differentiated hermeneutic approach is justified through a study of Luke's writing activity (transforming the teachings of Mt 24 and Mk 13 about the parousia event into exhortations about how to live ethically before the parousia) and of Jeremiah's ethical polyphony (which is evident in the divergent lifestyles affirmed by Jer $16: 2-4 ; 29: 6 ; 35: 6-7)$. It is argued that this multifaceted morality fits in with a balanced New Testament vision that characterizes Christians as both exiles and citizens (Heb 11:13-14; 1Pt 2:1).

Key Words: Luke; Jeremiah; Biblical ethics; Political interpretation; Redaction criticism; Intertextuality; Forced displacement; Migration.

\section{Cómo citar:}

Hays, Christopher M. “¿Buscar el bienestar de la ciudad, o marcharse mientras ella se quema? Lectura política e intertextual de Jr 29 y Lc 17 en relación con las crisis migratorias del siglo XXI". Theologica Xaveriana (2021): 1-30. https://doi.org/10.11144/javeriana.tx71.bbcmmq

\section{Reconocimiento}

El texto que se presenta aquí forma parte del proyecto "La misiología integral y el florecimiento humano de las personas en situación de desplazamiento interno en Colombia”, de la Fundación Universitaria Seminario Bíblico de Colombia. Dicho proyecto ha sido patrocinado principalmente por la Templeton World Charity Foundation, Inc.", que lo identifica con los números TWCF 0161 y TWCF0369, y se desarrolla entre el $1^{\circ}$ de junio de 2016 y el 16 de diciembre de 2022. No obstante, las opiniones expresadas en este artículo son del autor y no reflejan necesariamente las de las entidades antes mencionadas. 


\section{Introducción}

Lucas el evangelista (tal como el protagonista de su primera obra literaria) es bien conocido por su tendencia a subvertir expectativas socio-religiosas e invertir moralidades establecidas ${ }^{1}$, pero pocos han notado la aplicación de esta estrategia literaria en Lc 17,27-28. Allí, durante su primer discurso escatológico, el evangelista caracteriza a los coetáneos malvados de Noé y Lot como personas que "comían, bebían, se casaban y daban en casamiento [...] compraban, vendían, plantaban, construían” (17,27-28).

Dado que los habitantes de Sodoma y los miembros de la generación de Noé eran arquetipos de la maldad en la literatura judía (practicantes de vicios tan diversos como la fornicación, la bestialidad, la violencia, el robo, la blasfemia, la idolatría, el asesinato, la arrogancia, la violación, la glotonería y la falta de hospitalidad) ${ }^{2}$, por lógica, Lc 17 implica que las acciones aparentemente mundanas atribuidas a esos villanos son prácticas que los discípulos de Jesús deben repudiar, ya que, conforme con el v. 33, "todo el que procure preservar su vida, la perderá; y todo el que la pierda, la conservará". No obstante, parece altamente extraño condenar a los sodomitas y vecinos de Noé por alimentarse, criar familias y llevar una vida económica normal.

El exégeta entiende que, con esta maniobra retórica, el Jesús de Lucas se expresa de manera polémica, para generar en su audiencia un choque y señalar que una preocupación con las riquezas, la seguridad, la familia y los placeres materiales efectivamente desjarreta la disposición a seguir al Mesías sufriente, cargando la cruz, odiando la familia y renunciando los bienes (conforme con 14,25-33). Este argumento se ha elaborado en mayor detalle en otra publicación ${ }^{3}$ que se enfocó en el hecho de que las descripciones de los contemporáneos de Noé y Lot, en Lc 17, no se derivan de los retratos veterotestamentarios e intertestamentarios de aquellas desdichadas poblaciones. Pero aquel primer artículo nunca pasó a preguntar ¿de dónde derivó Lucas sus descripciones de tales generaciones malvadas, ya que las caracterizaciones de Lc 17 no se basan en Génesis?

El artículo actual propone una respuesta. Se argumentará que las descripciones de los coetáneos de Noé y Lot de Lc 17 hacen alusión a Jr 294. En este capítulo

\footnotetext{
${ }^{1}$ Véase, por ejemplo, a York, "The Last Shall be First. The Rhetoric of Reversal in Luke"; y a Verhey, The Great Reversal. Ethics and the New Testament.

${ }^{2}$ Hays, "Hating Wealth and Wives? An Examination of Discipleship Ethics in the Third Gospel", 59-62.

${ }^{3}$ Ibid., 54-58; 66-68.

${ }^{4}$ LXX Jr 36; la alusión tiene puntos de contacto con Jr 26-36, y el punto focal es el Capítulo 29. Cabe resaltar que Jr 26-36 es una subsección estructuralmente discreta en del libro. Véase a O’Connor, "Jeremiah", 510.
} 
veterotestamentario, el profeta les instruye a los exiliados en Babilonia a plantar y construir, tomar mujeres y dar sus hijas en casamiento. Sin embargo, con esta alusión, Lucas subvierte las expectativas morales de su audiencia: las instrucciones del Evangelio son directamente contrarias a las de Jeremías.

El profeta ordena: “... buscad el bienestar de la ciudad adonde os he desterrado [...] Porque en su bienestar tendréis bienestar” (Jr 29,7). Por su parte, Jesús advierte: "Acordaos de la mujer de Lot" (Lc 17:32), es decir, márchate de la ciudad mientras se quema y ni siquiera le eches un segundo vistazo. Este artículo se propone analizar precisamente la tensión entre estas dos exhortaciones proféticas, no solo para realizar un estudio intertextual, sino también para indagar en el potencial de esta antinomia intertextual y nutrir así la reflexión de comunidades de fe del siglo XXI sobre cómo negociar su vida de fe con relación a la sociedad.

En lo que sigue argumentaré que, cuando Lucas advierte que los días del Hijo de Hombre serán como los días de Noé y Lot ${ }^{5}$, las descripciones de los coetáneos de Noé y Lot como personas que plantaban y construían, casaban y daban en casamiento (17,26-30) funcionan como una alusión irónica a Jr 29,5-6, según la cual Lucas exhorta a sus oyentes a perder sus vidas para el Reino de Dios en vez de desperdiciarlas en preocupaciones por su "exilio" actual'. Esta maniobra intertextual lucana subvierte un texto veterotestamentario preciado que a menudo se considera normativo para comunidades de fe hoy, y genera enigmas hermenéuticos para intérpretes del siglo XXI, obligándonos a evaluar si debemos modelar la ética cristiana según el patrón recomendado por Jeremías, o por el de Lucas.

Aun si uno concluye que la alusión lucana de Jeremías solo existe "en los ojos de quien la mira”, desde una perspectiva canónica y/o de la estética de la recepción, las tensiones entre los estilos de vida exhortados por los dos textos bíblicos requieren de una exploración hermenéutica matizada, no sea que el testimonio de uno anule la perspectiva del otro. Así, después de argumentar que Lc 17 sí hace alusión a Jr 29, exploraré cómo aplicar los dos textos de maneras opuestas a dos crisis migratorias humanas en las Américas: el desplazamiento forzado interno en Colombia, por una parte, y la expulsión de migrantes indocumentados de los Estados Unidos, por otra.

\footnotetext{
5 Para un resumen del espectro de perspectivas sobre los significados del "día” y los "días" del Hijo de Hombre, véase a Lang, "'You Will Desire to See and You Will Not See [It]'. Reading Luke 17:22 as Antanaclasis", 284-287; y a Juza, "One of the Days of the Son of Man. A Reconsideration of Luke 17:22", 577-581.

${ }^{6} \mathrm{~N}$. T. Wright ha argumentado famosamente que la experiencia de una opresión continuada del pueblo de Dios bajo imperios gentiles se interpretaba como una continuación del exilio (Wright, The New Testament and the People of God, 268-271, 299-301).
} 
Para cerrar, reflexionaré sobre la justificación hermenéutica para este acercamiento diferenciado a la apropiación normativa de estos dos textos bíblicos.

\section{La subversión de Jr 29,5-7 por Lc 17,27-28}

Al comenzar con la indagación intertextual, ¿por qué imaginaría uno que Lc 17,27-28 hace alusión a Jr 26-36, y en particular a 29,5-7? Porque existen numerosas similitudes entre los textos, tanto por las situaciones generales que ellos enfrentan como por las actividades que abordan ${ }^{7}$.

\section{Puntos de contacto entre Jr 29 y Lc 17}

Para iniciar, los dos textos se dirigen hacia situaciones similares. En Lc 17,20-37, Jesús responde a preguntas sobre la hora de la venida del Reino de Dios, advirtiendo a sus discípulos en contra de los que identificarían su llegada de manera prematura con pronósticos sobre otros supuestos mesías (17,20-25). Jesús aclara que el Reino está incipientemente presente entre los discípulos $(17,21)^{8}$, aunque su revelación consumada con la venida del Hijo del Hombre aún se quedaba más alejada de lo que esperaban los discípulos $(17,30)$. De manera similar, Jr 29 refuta las profecías del regreso inminente a Jerusalén (Jr 28,8-10). Él explica que las bendiciones de la tierra prometida están disponibles de manera incipiente entre los judaítas en Babilonia (29,5-6), aunque el retorno a la tierra estaba más alejado de lo que esperaban los exiliados (29,10-14). Jr 29,12-14 dice que los judaítas desplazados encontrarían a Dios, no en Jerusalén sino en la misma Babilonia (v. 13: "Me buscaréis y me encontraréis").

\footnotetext{
${ }^{7}$ Desde la publicación de Richard Hays, Echoes of Scripture in the Letters of Paul (para un resumen de la recepción de libro, véase a Shaw, "Converted Imaginations? The Reception of Richard Hays's Intertextual Method”, 234-245), el gremio neotestamentario ha derramado cantidades de tinta discutiendo la diferencia entre una citación, una alusión y un eco del Antiguo Testamento en un texto del Nuevo Testamento, y sobre los criterios que se aplican para evaluar la percibida presencia de un eco o alusión en el texto bíblico (véase, por ejemplo a Porter, "Allusions and Echoes", 29-40; Beale, Handbook on the New Testament Use of the Old Testament. Exegesis and Interpretation, 29-40; Meek "Intertextuality, Inner-Biblical Exegesis, and Inner-Biblical Allusion. The Ethics of a Methodology", 284-290; Emadi, "Intertextuality in New Testament Scholarship. Significance, Criteria, and the Art of Intertextual Reading”, 8-23). Para los propósitos de este artículo, basta decir que la palabra "alusión" describe la invocación indirecta de un texto anterior, por medio de similitudes entre el lenguaje y las situaciones de los dos textos, escribiendo para una audiencia parte de la cual estaría en capacidad de identificar la referencia, en aras de afirmar o refutar la perspectiva del texto anterior.

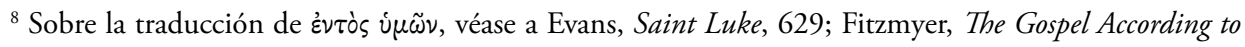
Luke (X-XXIV). Introduction, Translation, and Notes, 1161.
} 
Así mismo, Lc 17,21 afirma que aún antes de la venida del Hijo de Hombre, "el Reino de Dios entre vosotros estâ" pulos que no sean como la esposa de Lot, quien giró la mirada hacia atrás para ver de nuevo su ciudad natal destinada para destrucción (Lc 17,32; Gn 19,26), tal como Jeremías amonesta a los exiliados en Babilonia a no mantener sus esperanzas en Jerusalén, condenada a ruina aun en su época $(\mathrm{Jr} 29,17-20)^{10}$. En breve, estos dos textos presentan mensajes paralelos de una esperanza actual en situaciones de rescate diferido.

Estas situaciones análogas sugieren que los puntos de contacto específicos entre Lc 17 y Jr 29 (enumerados a continuación) no se deben dejar de lado como meras coincidencias. Como mostraré en seguida, tales puntos de contacto son numerosos, $\mathrm{y}$, aunque algunos de los temas mencionados en los cuatro pares asindéticos ${ }^{11}$ de actividades en Lc 17,26-30 -comer y beber, casar y dar en casamiento, comprar y vender, plantar y edificar- sí ocurren en otros pasajes del Antiguo Testamento, ningún texto combina tantos de ellos como lo hace Jr 29 (LXX Jr 36).

La evidencia más fuerte de una alusión a Jr 29 es el comentario en Lc 17,28 donde dice que las personas en los días de Lot plantaban y edificaban ( ஸ่xodónouv). Estos dos verbos, que forman el par asindético culminante de los vv. 27-28, constituyen una adición redaccional que Lucas introduce en su fuente mateana (Mt 24,36-40) ${ }^{12}$, con el efecto de evocar a Jeremías. "Plantar y edificar" es casi un lema de Jeremías, que es fundamental a su propio llamado profético: "Mira, hoy te he dado autoridad sobre las naciones y sobre los reinos, para arrancar y para derribar, para destruir y para derrocar, para edificar y para plantar" (Jr 1,10). Hay 21 textos

9 Lc 17,29.37 también comparte similitudes con Jr 34,20-22, ya que ambos textos hablan de quemar una ciudad con fuego y de aves del aire rodeando a cadáveres.

${ }^{10}$ Lc 21,5-6 deja en claro la destrucción venidera de Jerusalén. El enfoque del discurso escatológico en Lc 17 está principalmente en el juicio final. La destrucción de Jerusalén y el juicio final se vinculan de manera más directa en Mc 13 (la fuente primaria utilizada por Lucas en sus discursos escatológicos en los capítulos 17 y 21) pero no tan directamente en el tercer Evangelio, dado que Lucas, al escribier después de la caída de Jerusalén en el año 70 d. C., ya distingue entre estos dos eventos en aras de evitar la conclusión de que la profecía de Jesús había fallado; y Hays, "The Delay of the Parousia. A Traditional and Historical-Critical Reading of Scripture. Part 2", 81.

${ }^{11}$ Un "par asindético" es un par de palabras conectadas temáticamente, pero sin ninguna conjunción coordinante. Cabe aclarar que, al hablar de los antecedentes veterotestamentarios de estos pares, no se quiere implicar que los términos se combinan de manera asindética en al Antiguo Testamento; muy al contrario, se amplió la búsqueda bastante, recopilando todas las ocurrencias de los pares con una proximidad de veinte palabras, para no pasar por alto de referencias potencialmente relevantes.

${ }^{12}$ Según la teoría de relaciones sinópticas de Farrer-Goulder-Goodacre que respalda este estudio. Véase a Goodacre, The Case Against Q; Goodacre, The Synoptic Problem. A Way through the Maze; Goodacre, Goulder and the Gospels. An Examination of a New Paradigm. 
en el Antiguo Testamento en los que estos términos aparecen en proximidad uno al otro, nueve de los cuales están en Jeremías ${ }^{13}$.

Es especialmente intrigante de este par de actividades el que "plantar" y "edificar" no son intereses éticos significativos de Lucas (por lo menos no tanto como lo son los otros tres pares asindéticos). En otros contextos, Lucas es regularmente crítico de enredos económicos y familiares y de preocupaciones con la comida y la bebida, lo cual tal vez inclinaría a sus lectores a atribuir los primeros tres pares asindéticos a los intereses

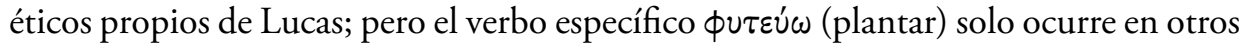
dos contextos en sus obras (Lc 13,9; 20,9), y en ambos textos la actividad de plantar no se describe de manera crítica; al contrario, en esos pasajes Dios es quien planta.

El verbo oixodo $\mu \varepsilon ́ \omega$ (edificar) ocurre con mayor frecuencia en Lucas y Hechos (Lc 4,29; 6,48-49; 7,5; 11,47-48; 12,18; 14,28.30; 20,17; Hch 7,47.49; 9,31; 20,32). Sin embargo, hay un único texto lucano que potencialmente se podría entender como crítica de edificar y es Lc 12,18. Este, de manera fascinante, se encuentra en la parábola del necio rico, quien construye graneros más grandes para almacenar su cosecha excepcional, y quien también es censurado por comer y beber (tema al cual volveré a continuación). Aunque Lc 12 refleja algunas de las mismas preocupaciones éticas subyacentes expresadas en 17,28 ${ }^{14}$, no constituye suficiente justificación para considerar "plantar" y "edificar" como retórica lucana negativa estereotípica, lo cual significa que la frase sigue siendo evidencia plausible de una alusión a Jeremías.

El segundo par - "casar" y "dar en casamiento" (Lc 17,27) - combina los verbos

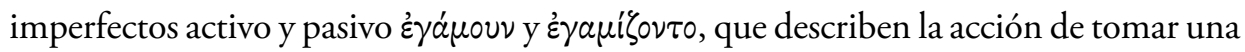
esposa propia y ser dada en matrimonio por el padre. Esta expresión griega concisa no ocurre en el Antiguo Testamento; al contrario, la típica expresión idiomática semítica es "tomar una mujer" y "dar" hijas a hombres. La combinación próxima de estas dos frases ocurre tan solo en cinco ocasiones en el Antiguo Testamento (Gn 34,16.21 [con

${ }^{13}$ Dt 6,10-11; 20,5-6; 28,30; Jos 24,13; Is 5,2; 65,21-22; Jr 1,10; 18,19; 29,5.28; 31,4-5.28; 35,7; 42,10; 45,4 [MT; 51,34 LXX]; Ez 28,26; 36,36; Am 5,11; 9,4; Qo 2,4; 3,2-3; 1Mc 3,5-6; Od 10,2; Sir 49,7 [lo cual es una alusión a Jeremías]. Este listado se compiló con base en búsquedas de pares de palabras con una proximidad de veinte palabras o menos, usando los pares de términos בנטע,

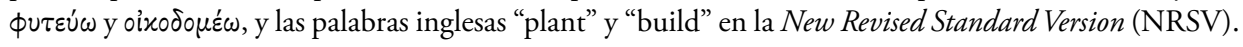

${ }^{14}$ Lc 12 usa imágenes de la economía agrícola para criticar una preocupación por proveer para necesidades dietéticas futuras. Por ejemplo, el rico construye graneros para embodegar una gran cosecha que fue el resultado de haber plantado previamente. De manera similar, las amonestaciones subsecuentes del discurso exhortan a los oyentes a no preocuparse por lo que se comerá, recordando que los cuervos ni siembran ni cosechan (12,22-24). 
Siquem]; Jc 3,6; 21,22; Jr 29,6) ${ }^{15}$ y el único texto que plausiblemente es relevante a Lc 17 es Jr 29,6 ${ }^{16}$. Todo ello indica que es altamente probable que la fuente de las idiosincráticas descripciones aplicadas a Sodoma y la perdida generación de Noé es la carta que Jeremías mandó a los exiliados en Babilonia.

\section{El trasfondo de Lc 17,27-38 más allá de Jr 29}

Reconocer estas similitudes marcadas, sin embargo, no nos obliga a limitar el trasfondo intertextual de Lc 17 exclusivamente al Capítulo 29 de Jeremías. Es del todo plausible imaginar que Lucas alimentó su lenguaje en 17,27-28 con conceptos derivados de un contexto veterotestamentario más amplio. Consideremos entonces los otros dos pares asindéticos: comprar y vender, y comer y beber.

\section{Comprar y vender}

El par "comprar" y "vender" (Lc 17,28) no es común en el Antiguo Testamento ${ }^{17}$ : aparece solo ocho veces (Gn 47,20.22; Lv 25,14-15.50; Ne 5,8; 10,31; Pr 23,23; Is 24,2; cfr. Si 27,2; 1Mc 12,36; 13,49), y ninguna de ellas parece temáticamente relevante a Lc $17^{18}$. Sin importar que Jr 29 no haga ninguna referencia a comprar y vender, el tema de comprar tierras sí emerge en Jr 32,6-15, cuando el profeta prevé un tiempo en el que "de nuevo se comprarán casas, campos y viñas en esta tierra" (Jr 32:15; cfr. 32,6-14). El texto continúa con la promesa de Dios:

Los reuniré de todas las tierras a las cuales los he echado en mi ira [...] y los haré volver a este lugar y los haré morar seguros $[\ldots]$ y ciertamente los plantaré en

${ }^{15}$ Este listado se compiló con base en búsquedas de pares de palabras con una proximidad de veinte

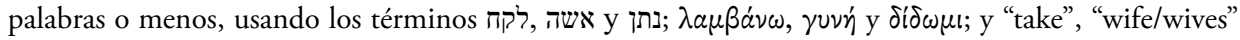
y "give" en la NRSV.

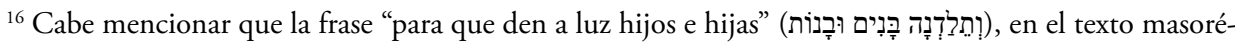
tico de Jr 29,6, no tiene equivalente alguno en Lc 17, pero también falta en el texto equivalente de la Septuaginta, Jr 36,6 (Duhm, Das Buch Jeremia. Kurzer Hand-Commentar zum Alten Testament, 229). Así, es posible que Lucas, quien dependía de la Septuaginta, ni siquiera conociera una forma de Jr 29,6//36,6 que incluía la frase "para que den a luz hijos e hijas", de modo que la ausencia de una alusión a esta frase en Lc 17 no pesa en contra de la alusión a Jr 29,5-6.

${ }^{17}$ Resultados basados en búsquedas de pares de palabras con una proximidad de veinte palabras o menos,

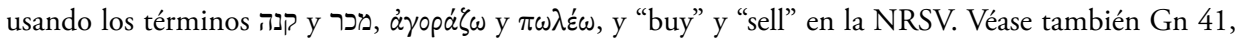
56-56; 42,5-6, los cuales usan terminología similar, aunque la distancia entre palabras cae justo por fuera del límite de veinte usado para la búsqueda.

${ }^{18}$ Existen paralelos cercanos en 2 Esd [4 Ezra] 16,41, pero los capítulos 15-16 de 2 Esd son adiciones cristianas que probablemente se remontan al tercer siglo d. C., de modo que no pueden ser la fuente de Lc 17,28 (Metzger, "The Fourth Book of Ezra”, 517, 520). 
esta tierra [...] La gente comprará campos por dinero, firmarán y sellarán escrituras y llamarán a testigos [...] porque restauraré su bienestar. (Jr 32,37.41.44)

Los puntos obvios de contacto temático entre Jr 29 y 32 (casas, campos, viñas, bienestar, etc.) indican que no es caprichoso percibir las referencias a transacciones económicas en el Capítulo 32 como evidencia adicional en favor de un trasfondo para Lc 17,27-28 en el libro de Jeremías ${ }^{19}$.

\section{Comer y beber}

En cuanto al par "comer" y "beber" (Lc 17,27-28), Jr 29,5 sí exhorta a los exiliados judaítas a comer de la cosecha de sus huertas, pero no menciona el acto de beber. Sin embargo, el beber es un tema enfatizado en el relato de los recabitas, en Jr 35,6.14, y es indudable que Jr 29 y 35 están temáticamente conectados, en la medida en que los recabitas son elogiados por observar el mandamiento de su antepasado de no beber vino ni construir casas ni plantar viñedos:

No beberemos vino, porque Jonadab, hijo de Recab, nuestro padre, nos ordenó, diciendo: "No beberéis vino jamás, ni vosotros ni vuestros hijos. No edificaréis casa, ni sembraréis simiente, ni plantaréis viña, ni poseeréis ninguna, sino que habitaréis en tiendas todos vuestros días, para que viváis muchos días en

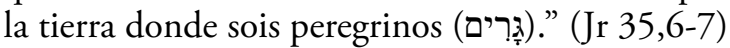

Así, se encuentra otro texto en la misma subsección de Jr 26-36 que combina los temas de plantar y edificar, y además incorpora el tema de beber. Todo esto suma para fortalecer el caso de que Lc 17,27-29 toma inspiración de Jeremías.

Los dos verbos "comer" y "beber" se emparejan con mucha frecuencia en la Biblia: más de cien veces en los dos testamentos ${ }^{20}$. En relación con este par específico es poco probable que Jeremías sea el único libro del Antiguo Testamento que nutrió la imaginación ética del evangelista, pues él ya había criticado las acciones de comer

${ }^{19}$ A pesar de todo esto, aunque los puntos de contacto entre Lc 17 y Jr 32 son significativos, no es esencial recurrir a Jeremías para explicar por qué Lucas incluyó el par de verbos "comprar" y "vender", ya que estas acciones son parte del interés económico que recurre a lo largo del tercer Evangelio. Lucas implícitamente critica la acción de comprar en 14,18-19, y las acciones de comprar y vender en 19,45 (Bock, Luke 9:51-24:53, 1433). Sin embargo, el otro contexto, que además es único, en el cual los dos verbos son emparejados es 22,36.

${ }^{20}$ Los candidatos más probables de alusión, evaluados exclusivamente con base en similitudes a Lc 17, son Qo 5,18; 8,15; 9,7; o alternativamente Am 9,14; Ag 1,6. Amós y Ageo esperan comer y beber en la restauración de Israel, mientras Qohélet anima a la gente a comer y beber en su estado actual. 
y beber tres veces en el discurso de Lc 12 (12.19.29.45), con miradas hacia otro texto veterotestamentario ${ }^{21}$.

Matthew Rindge ha demostrado de manera convincente que la parábola del necio rico hace alusión a Qohélet $(5,18 ; 8,15 ; 9,7)$ cuando el rico dice a sí mismo: "Alma, tienes muchos bienes depositados para muchos años; descansa, come, bebe, diviértete" (12,19). Y el Dios de la parábola execra al rico, diciendo: “¡Necio! Esta misma noche te reclaman el alma; y ahora, ¿para quién será lo que has provisto?" $(12,20)$. Con este comentario, Lucas subvierte la perspectiva sapiencial expresada en Qohélet (Qo 6,2; cfr. Sir 11,18-19; 14,3-6.14-16), según la cual uno no debe demorar en disfrutar de sus bienes materiales, por razón de no saber cuándo morirá. En contraste, Lucas sugiere que la incertidumbre de la hora de la muerte es una razón contundente para dividir sus bienes entre los pobres, no sea que uno no esté preparado para el momento en el que la muerte lo lleve al juicio ${ }^{22}$.

Así las cosas, es probable que la reaparición de los verbos "comer" y "beber", en Lc 17,27-28, continúa la misma línea de crítica desarrollada en Lc 12. Sin embargo, es instructivo mencionar cómo la parábola del joven rico subvierte a Qohélet. Argüiré a continuación que Lc 17 se acerca a Jr 29 de manera similar, indicando que una preocupación con enredos mundanos tales como plantar y edificar, casarse y dar en casamiento, a fin de cuentas, representa un fracaso en preparar de manera suficiente la llegada del Hijo de Hombre ${ }^{23}$.

\section{El mensaje de Jr 29: bendiciones del pacto, aun en el exilio}

A la luz de esta evidencia, una alusión a Jr 29,5-6 en Lc 17,27-28 es indudablemente plausible; pero antes de pasar a mostrar la relevancia de Jr 29 para Lc 17 se debe explicar el mensaje de Jr 29 mismo.

Jr 29 forma parte de una tradición en veterotestamentaria que describe las bendiciones del pacto en términos de plantar viñedos, construir casas y gozar de la familia y de la cosecha. Dt 28,1-14, por ejemplo, describe las bendiciones del pacto

${ }^{21}$ Sin embargo, las acciones de comer y beber son afirmadas en Lc 7,33-34; 10,7; 22,30 (este último versículo tiene un punto de referencia escatológico) son mencionadas, sin censura, en Lc 5,30.33; Hch 23,12.21.

${ }^{22}$ Rindge, "Illustrating Wisdom. Luke 12:16-21 and the Interplay of Death and Possessions in Sapiential Literature", 109-210, 212-219; Hays, Luke's Wealth Ethics. A Study in Their Coherence and Character, 126-127.

${ }^{23}$ De manera similar, Lc 17,7-10 se puede interpretar como una advertencia para que sus discípulos no dejen que su preocupación con comer y beber (entre otras cosas) en la época actual les distraiga de servir a su Señor; cfr. 12,45. 
en términos muy similares a los de Jr 29: "El Señor te hará abundar en bienes, en el fruto de tu vientre, en el fruto de tu ganado y en el producto de tu suelo, en la tierra que el Señor juró a tus padres que te daría" (Dt 28,11). En contraste, en los párrafos que siguen Deuteronomio pasa a advertir que la violación del pacto resultará en la pérdida de estas bendiciones, especialmente por medio del exilio (Dt 28,30.39.41; cfr. Am 5,11; So 1:13) ${ }^{24}$.

Te desposarás con una mujer, pero otro hombre se acostará con ella; edificarás una casa, pero no habitarás en ella; plantarás una viña, pero no aprovecharás su [...] Plantarás y cultivarás viñas, pero no beberás del vino ni recogerás las uvas, porque el gusano se las comerá [...] Tendrás hijos e hijas, pero no serán tuyos, porque irán al cautiverio. (Dt 28,30.39.41)

De manera similar, profetas como Isaías y Ezequiel esperan con ansias la restauración del exilio, cuando estas bendiciones del pacto se recuperarán (Is 65,21-22; Ez 28,26; 36,36; Am 9,14).

Aunque Jeremías comparte la expectativa de que todo pueblo de Dios gozará de estas bendiciones divinas en la época postexílica (Jr 31,17.27-29), él hace un anuncio sorprendente en su carta a los deportados judaítas en Babilonia: los exiliados en Babilonia continuarán -a pesar de su exilio- gozando de las bendiciones de casas, viñas y familias, en el mismo exilio, aunque las personas que se quedan en Jerusalén sufrirán las miserias de las maldiciones del pacto, maldiciones que (se imaginaría uno) "deben" recaer sobre los exiliados ${ }^{25}$.

Entonces el profeta exhorta a los exiliados a echar raíces en la diáspora y vivir de tal manera que busquen los beneficios de Dios en y para ${ }^{26}$ Babilonia $^{27}$. De manera

${ }^{24}$ 1Mc 3:5-6 también combina edificar, plantar y casarse en el mismo pasaje, en el contexto de no irse a la guerra, à la las exenciones del servicio militar delineadas en Dt 20.

${ }^{25}$ En Jr 27,8-13, el profeta indica (hablando ca. 597 a. C., bajo el rey Sedequías) que las personas en Jerusalén tenían la opción de quedarse en sus tierras sin perecer, si se sometían a Babilonia. Pero al llegar al Capítulo 29, se ha rescindido la oferta, por razón de que Dios había decidido destruir a Jerusalén completamente (587 a. C.) (Jr 29,17-19).

${ }^{26}$ En efecto, el texto anima los judíos a apoyar a sus vencedores (Sharp, Prophecy and Ideology in Jeremiah. Struggles for Authority in Deutero-Jeremianic Prose, 107; Schreiner, Jeremia II. 25, 15 - 52,34, 169; Carroll, Jeremiah. A Commentary, 555. Casey Strine, aprovechando de investigaciones de antropólogos de migración involuntaria, nota que los migrantes que viven en asentamientos geográficos aislados no suelen desarrollar fuertes vínculos personales recíprocos con la población anfitriona. Por otro lado, los migrantes que viven entre la población anfitriona desarrollan vínculos recíprocos e interpersonales con mayor facilidad (Strine, "Embracing Asylum Seekers and Refugees. Jeremiah 29 as Foundation for a Christian Theology of Migration and Integration", 482-483).

${ }^{27}$ Aquí hay algunas similitudes fascinantes con los consejos de Pablo para la iglesia en Tesalónica (1Ts 4, 11-12; 2Ts 3,10-13) (Rudolph, Jeremia. Handbuch zum Alten Testament, 155). 
fascinante, las promesas de las bendiciones del pacto y del shalom llegan a ser vigentes precisamente en el territorio de sus enemigos ${ }^{28}$, y Jeremías incluso emite un mandamiento -único en la Biblia hebrea ${ }^{29}$ - diciendo que los judaítas deben orar a favor de una nación pagana $(29,7)^{30}$.

En síntesis, aunque algunos aspectos de las bendiciones del pacto mencionadas en Jr 29 también aparecen en varios otros textos del Antiguo Testamento, es poco probable que uno de aquellos textos fuera la fuente del lenguaje que Lucas utiliza para describir las generaciones de Noé y de Lot en su primer discurso escatológico. Lc 17 tiene más puntos de contacto específicos con Jr 29 que con cualquier otro candidato intertextual (plantar, edificar, comer, casarse, dar en casamiento). Esto, en combinación con las situaciones paralelas de los dos textos que advierten a sus audiencias a no dejarse seducir por las proclamaciones falsas de un rescate inmanente, hacen de Jr 29 el candidato más probable de una alusión lucana.

\section{El mensaje de Lucas: asegurar su bienestar en el Reino venidero, no en Babilonia}

Entonces, al haber concluido que Lc 17 sí hace alusión a Jr 29 en sus descripciones de los estilos de vida de Sodoma y de los coetáneos de Noé, toca preguntar: ¿Cuál es el efecto de la alusión? La respuesta reside en el hecho de que el comportamiento atribuido a Sodoma y a la generación vil del diluvio ostensiblemente no es el comportamiento que los discípulos deben imitar. Lucas reconoce las similitudes entre las situaciones de los discípulos y de los exiliados judaítas, pero resiste cualquier suposición de que los discípulos recibirán todas las bendiciones del pacto en su época actual; en gran medida, la bendición llegaría en el ésjaton (así Lc 12,32-34.40-43; 14,14; pero nota también Lc 18,30).

Similar a los desplazados en Babilonia, los discípulos no se deben engañar de modo que supongan que su rescate de la opresión esté a la mano. A pesar de lo que indican los pronósticos de algunos charlatanes, la restauración escatológica todavía se queda en un futuro algo alejado. Sin embargo, a diferencia de los exiliados, los

\footnotetext{
${ }^{28}$ Allen, Jeremiah. A Commentary, 324.

${ }^{29}$ Carroll, Jeremiah. A Commentary, 553; Allen, Jeremiah. A Commentary, 324; Volz, Der Prophet Jeremia. Kommentar zum Alten Testament, 269; Rudolph, Jeremia. Handbuch zum Alten Testament, 155; en contraste, véase a Dt 23,7, que dice: “EEl pueblo de Israel jamás debe buscar el bienestar de los

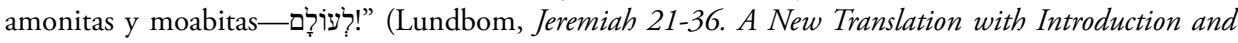
Commentary, 351).
}

${ }^{30}$ Esta orden casi presagia el mandamiento de Jesús a orar por sus propios perseguidores en Lc 6,27-28// Mt 5,43-44 (Weiser, Das Buch des Propheten Jeremia, 253). 
discípulos no deben echar raíces en "Babilonia" en expectativa del cumplimiento de las promesas del pacto. Para tal cumplimiento, tendrán que esperar un poco más de tiempo (cfr. Ap 6,10-11; Lc 22,30).

Jr 29,7 había exhortado a su audiencia: "Buscad el bienestar de la ciudad a donde os he desterrado, y rogad al Señor por ella; porque en su bienestar tendréis bienestar". De manera dramática, Lc 17,33 emite instrucciones opuestas: "Todo el que procure preservar su vida, la perderá; y todo el que la pierda, la conservará” (Lc 9,24-25). Lucas no excluye categóricamente la anhelada recompensa futura; más bien explica que, en el momento actual, los discípulos deben echar al lado tales enredos mundanos e imitar al Mesías sufriente mientras esperan su revelación escatológica $(17,25)$.

\section{Lecturas políticas de Jr 29 y Lc 17 en relación con dos crisis migratorias}

Esta interpretación intertextual, además de iluminar la destreza exegética de Lucas, ayuda a los lectores modernos a discernir tanto las similitudes como las diferencias entre las situaciones de Lucas y Jeremías. Ambos textos son dirigidos a personas que anhelan una liberación futura, y ambos critican a los que se atreven a predecir la llegada prematura de tal liberación.

Los dos autores escriben a comunidades bajo el dominio de imperios extranjeros, que no eran completamente opresivos ni completamente favorables a las poblaciones judías. Ambos textos están por lo menos parcialmente equivocados en sus pronósticos, ya que el rescate completo del exilio y el retorno de Cristo parecen haberse demorado mucho más de lo que estos dos autores bíblicos anticipaban ${ }^{31}$.

Ambos brindan consejos sobre cómo gestionar la vida económica y familiar mientras se espera el rescate, pero adoptan acercamientos marcadamente distintos: Jeremías instruye a su audiencia a comprometerse con el crecimiento de sus familias, el éxito de sus quehaceres económicos y el avance del bienestar de Babilonia, porque el florecimiento de su ciudad de residencia actual está íntimamente conectada con el florecimiento de los judíos. Lucas, en contraste, aboga por la renuncia de la familia y la vida económica en aras de ser completamente proactivo en buscar la voluntad de Dios antes de la llegada de la salvación escatológica ${ }^{32}$.

Estas visiones morales distintas generan preguntas desafiantes, pero potencialmente fructíferas en lo que se refiere a interpretar las Escrituras como éticamente

\footnotetext{
${ }^{31}$ Hays, "Prophecy. A History of Failure?", 23-38.

${ }^{32}$ Para más detalle, véase a Hays, Luke’s Wealth Ethics. A Study in Their Coherence and Character, 133-140; 166.
} 
normativas en diferentes situaciones históricas, en especial cuando uno lee un par de milenios después de la redacción de los dos textos, en una época en que se puede ver, con el beneficio de la mirada retrospectiva, que las expectativas de restauración de cada autor fueron por lo menos excesivamente optimistas.

En las Américas en el siglo XXI, por ejemplo, ¿debe uno adoptar el acercamiento de Jeremías, involucrándose completamente con la economía y la vida familiar y social de su ciudad, y creyendo que el bienestar propio depende del bienestar de la ciudad? ¿ $\mathrm{O}$ debe uno abandonar tales preocupaciones mundanas como distractores que afectan el compromiso con el Reino de Dios que amanece ya, como lo indica Lucas? Propongo afirmar la pertinencia de ambos acercamientos, dependiendo de la audiencia con y para la que uno lee. Para ilustrar este punto, exploraré dos crisis migratorias de las Américas en el siglo XXI.

\section{La pertinencia de Jr 29 para personas en situación de desplazamiento en Colombia}

La primera emergencia migratoria a la que me dirijo es la crisis del desplazamiento forzoso interno en Colombia ${ }^{33}$. En las últimas décadas, ocho millones de colombianos $-15 \%$ de la población nacional- han sido expulsados de su tierra y sus casas por el conflicto violento entre grupos guerrilleros, fuerzas paramilitares, los carteles y las fuerzas públicas ${ }^{34}$. En efecto, refugiados dentro de sus propias fronteras nacionales, la gran mayoría de esas personas en situación de desplazamiento (PSD) huyen del campo a las ciudades buscando (no siempre encontrando) alivio de la violencia. Por razón del trauma psicológico y cultural que sufrieron y la incompatibilidad de sus habilidades agrícolas con el mercado laboral urbano, en Colombia, las personas en situación de desplazamiento a menudo se estancan en sus sitios de llegada ${ }^{35}$; y con una tasa de extrema pobreza del $85 \%$, típicamente sueñan con nostalgia acerca de la vida que perdieron, a la vez sabiendo que no pueden volver a casa de nuevo ${ }^{36}$.

${ }^{33}$ Colombia también está enfrentando una crisis de migración de refugiados venezolanos, y mucho del argumento de esta sección aplicaría a ellos también.

${ }^{34}$ Red Nacional de Información, "Registro Único de Víctimas”.

${ }^{35}$ Sobre las consecuencias psicológicas y sociales del desplazamiento, véase a Cadavid Valencia, "Elementos para comprender el desplazamiento forzado en Colombia. Un recorrido por normas, conceptos y experiencias", 18-24; Rojas-Flores, "Desplazamiento de centroamericanos y colombianos. Violencia, trauma y el ministerio de la Iglesia”, 27-35; Amparo Camilo, "Impacto psicológico del desplazamiento forzoso. Estrategia de intervención", 27-40.

${ }^{36}$ Sobre las ramificaciones económicas del desplazamiento forzoso en Colombia, véase a Hays, "Justicia económica y la crisis del desplazamiento interno en Colombia", 45-52; Ibáńez y Vélez, "Civil Conflict 
A menudo se encuentran psicológica, económica y espiritualmente incapaces de crear un hogar en su nuevo contexto. Llegan a ser, en sentido real, exiliados aun dentro de la nación de la cual son ciudadanos.

El autor de este artículo es director de "Fe y Desplazamiento", proyecto de investigación-acción participativa en Colombia que pretende movilizar el capital humano de las iglesias evangélicas colombianas en aras de fomentar la recuperación integral de las víctimas del conflicto armado ${ }^{37}$. En nuestro trabajo, el mensaje que comunicamos a las personas en situación de desplazamiento de Colombia es el mismo mensaje que Jeremías comunicó en medio de los deportados judaítas en Babilonia: plantar y edificar ${ }^{38}$.

Tal como Jeremías urgió a los desplazados en Babilonia a no quedarse indolentes esperando que su pronto regreso a Jerusalén, así también las personas en situación de desplazamiento de Colombia con frecuencia necesitan ayuda para escapar del torpor que resulta al ser espiritual, psicológica y culturalmente desamparadas. Ya que no es realista que la mayoría de ellas vuelvan a la tierra que dejaron atrás ${ }^{39}$, las opciones disponibles son, o echar raíces o desecarse y marchitarse. Sin embargo, las personas en situación de desplazamiento de Colombia, así como los evangélicos colombianos en términos más generales, a menudo requieren de apoyo para llegar a percibir a la ciudad y el Estado como aliados potenciales, como grupos colectivos cuyo bienestar muy posiblemente puede ser compatible con su propio bienestar ${ }^{40}$.

and Forced Migration. The Micro Determinants and Welfare Losses of Displacement and Colombia", 659-766; Ibáńez y Moya, "Do Conflicts Create Poverty Traps? Asset Losses and Recovery for Displaced Households in Colombia”, 137-172.

${ }^{37}$ Para una introducción a la teoría del proyecto, véase a Hays, "El discipulado de los laicos para el servicio integral en el mundo. Un experimento misiológico evangélico a favor de las personas en situación de desplazamiento en Colombia”, 13-32. Los materiales creados por el proyecto están disponibles en www.feydesplazamiento.org.

${ }^{38}$ Véase, por ejemplo, a Hays y Ramírez, La esperanza económica después del desplazamiento forzoso. Manual del facilitador, 44-47.

${ }^{39}$ Sin menospreciar el programa de restitución de tierras, toca reconocer que solo 66.000 personas (menos de $1 \%$ de la población desplazada total) se han beneficiado del proyecto (Unidad de Restitución de Tierras, "Estadísticas de restitución de tierras"). Además, los reclamantes de tierras y los líderes que promueven restitución de tierras siguen siendo amenazados y asesinados (Lozano S., "Reclamantes de tierras y líderes sociales. Un asesinato por día”).

${ }^{40}$ El Estado ha reconocido que la catástrofe humanitaria del desplazamiento forzado requiere de atención gubernamental; así, el Ejecutivo y el Congreso de Colombia promulgaron las leyes 387 de 1997 sobre Atención Integral a la Población Desplazada; 975 de 2005 sobre Justicia y Paz; y 1448 de 2011 sobre Víctimas y Restitución de Tierras. La Corte Constitucional también ha reconocido la prioridad de la atención especial del Estado a las personas en situación de desplazamiento, con la Sentencia T-025 de 2004, en la que declaró "la existencia de un estado de cosas inconstitucional en la situación 
En Colombia, los cristianos evangélicos han sido minoría durante mucho tiempo, incluso una minoría perseguida (en especial antes de la Constitución de 1991), de modo que no suelen confiar fácilmente en la benevolencia del gobierno (aunque esta dinámica se va cambiando ya que los evangélicos se están reconociendo como un electorado clave en el país $s^{41}$. Sin embargo, cuando nuestro equipo de trabajo en "Fe y Desplazamiento" reflexiona sobre las personas víctimas de la violencia y la pobreza extrema en Colombia, y mientras nos preguntamos qué se puede hacer para apoyar de manera óptima su recuperación, es difícil evitar la conclusión de que debemos apoyarles en realizar el equivalente moderno de plantar y edificar, a integrarse en sus nuevos contextos urbanos, a buscar una cooperación productiva con la ciudad pues su bienestar está ligado al bienestar de la ciudad ${ }^{42}$.

Esta perspectiva no se radica en ningún optimismo facilista que pretende que el Estado colombiano sea un agente divino (en contraste con, por ejemplo, Is 45,1-7), sino en la convicción de que esta es la manera más eficaz de aliviar el sufrimiento de muchas de estas víctimas. Así, cuando predico y enseño en comunidades de personas en situación de desplazamiento de Colombia, predico Jr $29^{43}$.

de la población desplazada debido a la falta de concordancia entre la gravedad de la afectación de los derechos reconocidos constitucionalmente [...] de un lado, y el volumen de recursos efectivamente destinado a asegurar el goce efectivo de tales derechos y la capacidad institucional para implementar los correspondientes mandatos constitucionales y legales, de otro lado". La Corte mantiene la presión sobre el Ejecutivo para el resarcimiento de los derechos constitucionales de los desplazados, mientras que este reitera: "El Estado no tiene capacidad para atender a todas las víctimas al mismo tiempo" (Presidencia de Colombia). Esta coyuntura prolonga la victimización de los desplazados y los expone a la profundización de su pauperización.

${ }^{41}$ Beltrán, "El voto evangélico, el nuevo botín electoral”; El Tiempo, "El voto cristiano, una cantera dispersa en las elecciones".

${ }^{42}$ Aunque este artículo no está enfocado en temas del estatus jurídico de las PSD, ni en las obligaciones del Estado frente las PSD, por nada pretende justificar el quietismo político. Existen diversos ejemplos de iglesias evangélicas que inciden políticamente frente el conflicto armado. Véase, por ejemplo, el resumen bibliográfico de Quezada Plata y Vega Rincón, "Religión, conflicto armado colombiano y resistencia”, 137-148, o más concretamente considere las recomendaciones políticas hechas por las iglesias menonitas de Colombia, en Justapaz y Comisión de Paz del Consejo Evangélico de Colombia (Cedecol), Un llamado profético. Las iglesias colombianas documentan su sufrimiento y su esperanza. Informe 4, 103-109. En el contexto del proyecto Fe y Desplazamiento, se han producido recursos para la movilización política tanto de las iglesias evangélicas como de las mismas poblaciones en situación de desplazamiento (Heimburger y otros, Iglesia, política y desplazamiento. Cartilla para profesionales; Heimburger y otros, Iglesia, politica y desplazamiento. Currículo para personas en situación de desplazamiento).

${ }^{43}$ Las reflexiones de Davidson sobre Jr 29 también son pertinentes a la situación de las PSD de Colombia: "Sin la tierra como la base para definir la identidad, la comunidad deportada depende de las instituciones de familia y religión como mecanismos para perpetuar su existencia en un contexto nuevo. Así, la comunidad utiliza estrategias de adaptación para establecer un hogar no determinado 


\section{Una visión lucana para los evangélicos estadounidenses, ante las controversias migratorias}

No obstante, la visión bíblica que es más pertinente a las personas en situación de desplazamiento de Colombia probablemente no es el mensaje que muchos norteamericanos necesiten escuchar; para explorar este tema, cambiemos de crisis migratorias y audiencias objetivo, viajando hacia el norte del Río Grande. Aunque iglesias protestantes en las Américas suelen interpretar Jr 29 como moralmente programático, las barbaridades realizadas por la agencia estadounidense Immigration and Customs Enforcement, ICE ${ }^{44}$, y a petición de un gran porcentaje de ciudadanos estadounidenses, sugieren que el mensaje de Lc 17 es más pertinente a aquella población.

Por ser el presente teólogo un evangélico estadounidense blanco, me causa horror que aproximadamente la mitad (el $51 \%$ ) de los evangélicos blancos favorecen las políticas recientes que categorizan a inmigrantes sin documentos como criminales y justifican la separación de los niños de sus padres (en contraste, el $74 \%$ de los católicos y el $87 \%$ de los evangélicos no blancos se oponen a la separación de las familias en la frontera $)^{45}$.

Según un estudio de la Public Religion Research Institute, aunque la mayoría de los cristianos se opone a la legislación que prohibiría a refugiados de entrar en los Estados Unidos (el $56 \%$ de los católicos, el $55 \%$ de protestantes blancos de denominaciones históricas, el $63 \%$ de protestantes no blancos), los evangélicos blancos son "valores atípicos" (outliers), de manera ignominiosa, en relación con el tema (siendo igualmente divididos: el $44 \%$ a favor, y el $44 \%$ en contra $)^{46}$.

Las razones dadas para oponerse a los migrantes indocumentados son teológicamente reveladoras: aunque se aducen muchas en apoyo de la deportación de los inmigrantes latinos indocumentados, dos surgen con mayor frecuencia ${ }^{47}$. La primera: que los inmigrantes latinoamericanos representan un desafío económico para los ciudadanos estadounidenses, especialmente en la medida en la que se perciben como fuente de competencia en el mercado laboral o drenaje de los fondos sociales nacionales. La segunda preocupación consiste en que los inmigrantes latinoamericanos supuestamente

solo por espacio geográfico" (Davidson, Empire and Exile. A Postcolonial Reading of Jeremiah, 170-171; traducción del autor).

${ }^{44}$ Grace Meng, "ICE Raids on US Immigrant Families Risk Serious Abuses”.

${ }^{45}$ Cox, "Growing Divide on Immigration and America’s Moral Leadership".

${ }^{46} \mathrm{Ibid}$.

${ }^{47}$ Para un listado más completo, véase a Nowrasteh, "The 14 Most Common Arguments against Immigration and Why They're Wrong". 
representan una amenaza a la seguridad de las familias no inmigrantes. El presidente Trump, cuando era un candidato, dio voz a los sentimientos de muchos ciudadanos al decir, "Ellos están ingresando drogas. Están ingresando drogas. Son violadores"48. Más recientemente, expresó: "Hay muchas personas entrando al país [...] Ustedes no creerían qué tan malvados son estas personas. No son personas. Estas son animales" ${ }^{4}$.

Al pasar por encima del hecho de que estos temores son factualmente mal informados ${ }^{50}$, tales razones primarias para apoyar la deportación de inmigrantes indocumentados son síntomas de las suposiciones teológicas de muchos evangélicos blancos. A fin de cuentas, las preocupaciones sobre la inmigración reflejan una fijación en la seguridad financiera y familiar, a expensas de justicia y misericordia para el forastero y extranjero.

Así parece razonable sugerir que el mensaje que los cristianos evangélicos blancos en los Estados Unidos necesitan escuchar más no es la carta que Jeremías escribió a los exiliados judaítas en Babilonia (ya que, en esta situación, los cristianos estadounidenses son análogos a los ciudadanos de Babilonia) sino el discurso escatológico de Lucas, en el cual Jesús exhorta a sus discípulos a no dedicarse tanto a asegurar sus familias y finanzas en esta época al punto que terminen fallando en prepararse por la época venidera, efectivamente falsificando la afirmación de Jesús, "he aquí, el Reino de Dios entre vosotros está" (Lc 17:2; cfr. 9:25).

Naturalmente, estas dos lecturas políticas recomiendan acercamientos y acciones en tensión mutua. Esto nos lleva la pregunta con la que propongo concluir este artículo: ¿Existe alguna justificación para estas maniobras hermenéuticas diferenciadas?

${ }^{48}$ Traducción del autor. Discurso de campaña del presidente Donald Trump, el 16 de junio de 2015; para análisis, véase a Philips, “'They’re Rapists.' President Trump’s Campaign Launch Speech Two Years Later, Annotated".

${ }^{49}$ Traducción del autor. White House, "Remarks by President Trump at a California Sanctuary State Roundtable".

${ }^{50}$ Los inmigrantes no suben la tasa de delincuencia (Nowrasteh, "By the Numbers: Do Immigrants Cause Crime?"; Martínez y Lee, "On Immigration and Crime”, 485-524; Mears, "Immigration and Crime: What's the Connection?" 284-288; Butcher y Morrison Piehl, "Crime, Corrections, and California: What Does Immigration Have to Do with It?", 1-23. Además, inmigrantes indocumentados hacen significativas contribuciones netas a los programas estatales de bienestar, y tienen un efecto nimio en los sueldos y tasas de empleo de los ciudadanos (Zallman, Woolhandler, Himmelstein, Bor y McCormick, "Immigrants Contributed An Estimated \$115.2 Billion More to the Medicare Trust Fund than They Took out in 2002-2009”, 1153-1160; Nowrasteh, “The 14 Most Common Arguments against Immigration and Why They're Wrong"; Ku y Bruen, "Poor Immigrants Use Public Benefits at a Lower Rate than Poor Native Born Citizens", 1-8). 


\section{La justificación hermenéutica para lecturas políticas diferenciadas de Jr 29 y LC 17}

A pesar de las diferencias entre las perspectivas y contextos históricos de Jeremías y Lucas, un examen cuidadoso de estos mismos textos revela que sus propios procesos redaccionales brindan antecedentes canónicos para las lecturas divergentes de las Escrituras que este artículo ha elaborado en relación con las controversias migratorias en los Estados Unidos y en Colombia.

\section{La historia redaccional de Lc 17: contextualización de la tradición}

Al comenzar el tercer Evangelio, la crítica de la redacción indica que Lc 17 ha reformulado las palabras de Jesús conforme con la situación histórica del evangelista y los mensajes morales más pertinentes a su audiencia. Según la hipótesis Farrer-Goulder-Goodacre, Lucas derivó la mayoría de su material de Mt 24; pero este material fue inicialmente añadido por Mateo al contenido del discurso de los Olivos en Mc 13. Y tal como en el discurso de los Olivos de Marcos, Mt 24 vincula la destrucción del templo más o menos directamente a la segunda venida del Hijo del Hombre.

Lucas, sin embargo, al escribir varios años después de Mateo, es más sensible al lapso transcurrido entre la destrucción de Jerusalén y el regreso del Hijo del Hombre que se seguía esperando, así que escinde de Mt 24 el material M sobre el regreso del Hijo del Hombre, y añade a este las referencias a la esposa y los coetáneos de Lot (Lc 17,28-29.31). Así, Lucas crea un nuevo discurso escatológico en el Capítulo 17 de su Evangelio (y deja el material del discurso de los Olivos para su segundo sermón escatológico en el Capítulo 21, en el cual él también hace varios ajustes para suavizar el problema de la brecha temporal entre la caída de Jerusalén y el regreso del Hijo de Hombre) $)^{51}$.

\footnotetext{
${ }^{51}$ Este sermón escatológico de Lc 21 se desarrolla en paralelo a Mc 13,1-32, el cual sí combina profecías de la destrucción de Jerusalén (Mc 13,1-27//Lc 21,1-27) con señales de la venida del Hijo de Hombre (Mc 13,28-32//Lc 21,29-33). Pero Lucas hizo ajustes claves a este texto para ampliar la brecha entre la caída de Jerusalén y el regreso del Hijo de Hombre: (1) Lucas eliminó de Mc 13,29 ("cuando veáis

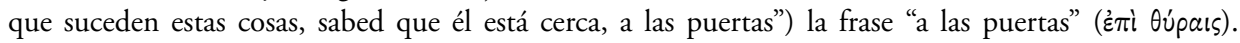
(2) Lucas removió Mc 13,20 ("Y si el Señor no hubiera acortado aquellos días, nadie se salvaría; pero por causa de los escogidos que él eligió, acortó los días"). (3) Lucas reubicó las advertencias de no seguir a mesías falsos (Mc 13,21-23), colocándolas en el discurso escatológico de Lc 17. (4) Finalmente, Lucas

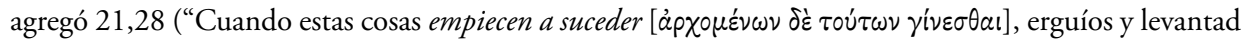

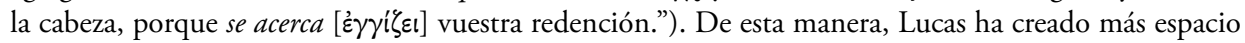
entre la destrucción de Jerusalén en 70 d. C. (evento que él describe en cap. 21) y el regreso de Cristo (descrito en el Capítulo 17) para acomodar el hecho de que, cuando él escribe el Evangelio en los
} 
En breve, Lc 17 remodela la tradición $\mathrm{M}$, transformándola de un enseñanza sobre el evento de la parusía misma ${ }^{52}$ a una exhortación moral sobre cómo vivir de manera ética antes de la parusía ${ }^{53}$. De esta forma, Lucas explica el retraso (desde su perspectiva, moderado) de la parusía, manteniendo su expectativa de la segunda venida de Cristo -e identifica simultáneamente cumplimientos parciales de la profecía de Jesús $^{54}$ - pero moldeando las tradiciones de Jesús para brindar dirección ética a su comunidad mientras esperaba su retorno.

Dicho de otra manera, Lucas reconocía que el retraso de la parusía y la situación ética que su audiencia enfrentaba requerían la adaptación de la tradición normativa en maneras que afirmaban el depósito revelador y/o central de la tradición (es decir, la certidumbre del retorno de Cristo) y a la vez posibilitaban que aquella tradición hablara más directamente a las circunstancias históricas de su comunidad (específicamente, a los cristianos que estarían indebidamente preocupados con temas financieros y familiares) $)^{55}$.

Este análisis redaccional sirve como precedente para mi propia lectura política de Jr 29 y Lc 17 para el siglo XXI. Por una parte, dado que la parusía ya se ha demorado un poquito más de lo que Lucas aparentemente esperaba (véase, por ejemplo, a Lc 9,31; 21,33), se puede defender la decisión de aplicar Jr 29, y no Lc 17, a la

años 80 , Jesús todavía no había regresado. Aunque esto quizás no contesta todas las preguntas que el retraso de la parusía genera para lectores del siglo XXI, probablemente fue un ajuste adecuado para aplazar el problema de la demora en la segunda venida en la época del evangelista.

${ }^{52}$ Lc 17 también elimina de Mt 24 las frases enfocadas en la incertidumbre de la hora de la venida del Hijo de Hombre, ya que su interés está no en cuándo vendrá el Hijo del Hombre, sino en cómo vivir

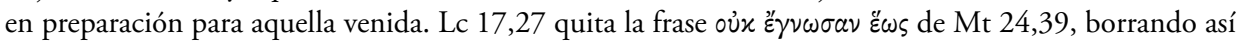
el énfasis en la ignorancia de la hora y fecha del retorno de Jesús. En la misma línea, Lc 17 no incluye ningún paralelo a Mt 24,42-44, versículos centrados en la incertidumbre de la hora de la venida del Hijo de Hombre (Lucas colocó estos versículos en 12,39-40 de su Evangelio), dado el enfoque lucano en la ética necesaria para preparar para la segunda venida, y no la hora del evento.

${ }^{53}$ Hays, "Hating Wealth and Wives? An Examination of Discipleship Ethics in the Third Gospel", 64-65.

${ }^{54}$ Hays y Ounsworth, "The Delay of the Parousia. A Traditional and Historical-Critical Reading of Scripture. Part 1", 69-76; Hays, "The Delay of the Parousia. A Traditional and Historical-Critical Reading of Scripture. Part 2”, 81.

55 De manera similar, la narrativa de los recabitas, en Jr 35, también subraya la necesidad de adaptar la tradición autoritativa conforme con las nuevas circunstancias histórico-políticas. Como dice Mark Leuchter: "La narración claramente describe el valor de adherir a la palabra de Jeremías y el mérito de sostener la tradición por medio de la adaptación en tiempos de necesidad [...] Los recabitas desafían su directivo tradicional a seguir siendo nómadas, pero su morada urbana surge solo de la necesidad; esta decisión no implica ninguna falta de convicción, la cual ellos afirman enfáticamente (vv. 7-10) [...] Los recabitas demuestran piedad verdadera por adherirse al espíritu de los mandatos de su padre en mareas cambiantes" (Leuchter, Polemics of Exile in Jeremiah 26-45, 98. Traducción del autor: énfasis agregado). 
situación de las personas en situación de desplazamiento en Colombia. Ya que tenemos una base de experiencia razonable para esperar que tales personas se quedarán en su exilio terrenal actual un poco más de tiempo, esperando la segunda venida de Cristo ( $\mathrm{u}$ otra intervención menos celestial!), se justifica animarlas a reestablecer una medida de estabilidad económica y familiar sin sentir que están arbitrariamente rechazando las amonestaciones que Lucas hace: que un discípulo deba perder la vida para asegurarla $(17,23)$.

Por otra parte, al afirmar la convicción fundamental de Lucas en relación con el retorno eventual de $\mathrm{Cristo}^{56}$-aun si ya contamos con la retrospección histórica como justificación para discrepar de los autores sinópticos sobre el grado de inminencia que ellos esperaban con relación a aquel retorno ${ }^{57}$-, uno puede mantener una fuerte justificación para criticar una audiencia evangélica norteamericana que expulsa a migrantes indocumentados en aras de fortalecer su propia seguridad y bienestar económico. En otras palabras, la misma historia de redacción de Lc 17 brinda la justificación epistémica para querer quedarme con el pan y la torta (es decir, enfatizar en diferentes componentes del texto bíblico en aras de responder de manera diferenciada a las vicisitudes de las situaciones históricas de distintas audiencias).

\section{Afirmación de diferentes estilos de vida en Jeremías}

Segundo, el libro de Jeremías también brinda un precedente para el método interpretativo de este artículo. A lo largo de ese texto, el profeta recomienda distintos estilos de vida para personas de herencias culturales particulares y en ubicaciones geográficas distintas. En marcado contraste con sus exhortaciones a los exiliados judaítas - “Tomad mujeres y engendrad hijos e hijas" (Jr 29,6)-, Dios ordena a Jeremías mismo:

No tomes para ti mujer ni tengas hijos ni hijas en este lugar. Porque así dice el Señor acerca de los hijos e hijas nacidos en este lugar, y acerca de las madres que los dieron a luz [...]: de muertes crueles morirán; no serán llorados ni sepultados; serán como estiércol sobre la faz de la tierra; a espada y por hambre

\footnotetext{
${ }^{56}$ De esta manera, difiero de Hans Conzelmann, quien aseveró que la lucha teológica fundamental de Lucas fue esencialmente antiapocalíptica (Conzelmann, The Theology of St. Luke, 123), ya que, según mi perspectiva, Lucas sigue esperando la restauración escatológica y apocalíptica de todas las cosas. Sin embargo, tengo ciertas simpatías con Conzelmann cuando él dice (sin duda demasiado encarecidamente): "El factor primario en la refundición que Lucas aplica a su fuente es el retraso de la parusía, la cual genera una reconsideración comprensiva de la naturaleza y secuencia de las últimas cosas [...] Ya que el final queda lejos, el acomodarse a una espera breve se remplaza por una "vida cristiana" de larga duración, la cual requiere regulación ética y no depende más de un final definido" (ibid., 131-32, traducción del autor). ${ }^{57}$ Hays, "Introduction? Was Jesus Wrong about the Eschaton?", 3-18; Hays, "Prophecy. A History of Failure?”, 33-37.
} 
serán acabados, y sus cadáveres servirán de comida para las aves del cielo. (Jr 16,2-4)

Aunque estas instrucciones se dirigen específicamente a Jeremías, su lógica depende del mensaje que afirma que, quienes se quedan en Jerusalén, sufrirán y perecerán. En contraste con los judaítas en Babilonia, animados en 29,5-7 a casarse y engendrar nińos ya que florecerán en el exilio, en 29,15-23, las personas que se quedan en Jerusalén son descritas como "higos reventados" ${ }^{88} \mathrm{y}$ advertidas de persecución con "la espada, el hambre y la pestilencia", ya que no hicieron caso a la Palabra del Señor y sus profetas $(29,19)^{59}$. Y en dicha situación de sufrimiento es mejor no gozar de la bendición de niños (Lc 12,23).

Jeremías cambia su énfasis otra vez después de un par de capítulos, cuando habla con los recabitas, un grupo de migrantes involuntarios que buscan refugio en Jerusalén ${ }^{60}$. Los recabitas eran descendientes de Yehonadab ben Recab, un yahvista rigorista (presentado en 2R 10,15-28) ${ }^{61}$, quien había mandado a sus hijos: "No beberéis vino jamás [...] No edificaréis casa, ni sembraréis simiente, ni plantaréis viña, ni poseeréis ninguna, sino que habitaréis en tiendas todos vuestros días, para que viváis

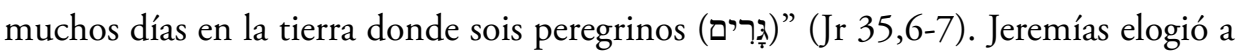
los recabitas por su fidelidad a los preceptos de su antepasado y les asegura que "no le faltará hombre que esté delante de [el Señor] todos los días" (35,18-19).

Así, Jeremías recomienda aun otra manera de vivir, bien opuesta a la existencia agrícola sedentaria encomendada a los judaítas en Babilonia; pero a pesar de que se les dijo a los recabitas que no deben plantar y edificar, precisamente en aras de quedarse en la tierra, a ellos se les promete una bendición divina ${ }^{62}$. En resumen, Jeremías promociona estilos de vida que son dramáticamente diferentes, incluso opuestos, para diferentes grupos, dependiendo de su ubicación geográfica (en la tierra, fuera de la

\footnotetext{
${ }^{58}$ Con esta expresión, el profeta reanuda una imagen del Capítulo 24, en el cual ya había denigrado la comunidad en Jerusalén y afirmado la superioridad de los exiliados con relación a los que se quedan en la tierra (Davidson, Empire and Exile. A Postcolonial Reading of Jeremiah, 141-43).

${ }^{59}$ Carroll, Jeremiah. A Commentary, 562; Thompson, The Book of Jeremiah, 548.

${ }^{60}$ Strine, "Embracing Asylum Seekers and Refugees. Jeremiah 29 as Foundation for a Christian Theology of Migration and Integration", 484.

${ }^{61}$ Leuchter, Polemics of Exile in Jeremiah 26-45, 95.

${ }^{62}$ Los recabitas representan un estilo de vida alternativo al modus vivendi al que los jerosolamitas se aferraban (Davidson, "Exoticizing the Otter'. The Curious Case of the Rechabites in Jeremiah 35", 205-206).
} 
tierra), herencia cultural (recabita o no) y fidelidad a los preceptos de sus antepasados y los profetas $^{63}$.

Así las cosas, parece no meramente justificado pero quizás necesario aplicar el mensaje de Jr 29 de manera afirmativa a las personas en situación de desplazamiento de Colombia, animándolas a echar raíces en sus sitios de llegada. Simultáneamente, se debe subrayar la crítica de preocupaciones familiares y financieras en Lc 17 para una audiencia evangélica norteamericana que se opone a los inmigrantes indocumentados por razón de su interés en el bienestar de sus familias (que ya son privilegiadas en términos globales).

\section{Perspectivas neotestamentarias sobre extranjería y ciudadanía espiritual}

Tercero y finalmente, al tomar en cuenta el contexto más amplio del canon del Nuevo Testamento, otros textos manifiesten una visión equilibrada de la identidad de los cristianos como exiliados y a la vez ciudadanos, la cual es pertinente al acercamiento hermenéutico de este artículo.

La Epístola a los Hebreos y la primera Epístola de Pedro describen a los miem-

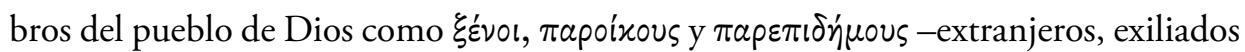
y peregrinos-, y enfatizan en que los cristianos no deben sentirse demasiado cómodos en sus ciudades y naciones actuales, para recordarles que su ciudadanía está en el Reino venidero (Hb 11,13-14; 1P 2,11; cfr. 1,1). Sin embargo, 1 Pedro (cfr. Ep. Diog. 5,1-5) anima a su audiencia de exiliados espirituales (aunque probablemente no son exiliados en el sentido político-geográfico) a vivir como ciudadanos honorables y constructivos en un imperio que de veras no es su hogar, y lograr así un equilibrio entre la edificación de la ciudad sin sacrificar la lealtad al reino del que de veras son ciudadanos ${ }^{64}$.

Esta visión equilibrada de la identidad cristiana es suficientemente amplia para incorporar tanto las exhortaciones a las personas en situación de desplazamiento colombianas, con base en Jr 29, como las advertencias a los evangélicos norteamericanos, con base en Lc 17.

\footnotetext{
${ }^{63}$ Keown, Scalise y Smothers, Jeremiah 26-52, 71.

${ }^{64}$ Strine, "Embracing Asylum Seekers and Refugees. Jeremiah 29 as Foundation for a Christian Theology of Migration and Integration", 488-489. Para más sobre la perspectiva de 1P de los cristianos viviendo en un mundo hostil, véase a Horrell, 1 Peter, 85-95.
} 


\section{Conclusiones}

En conclusión, he argumentado que Lc 17, en la descripción de las generaciones de Noe y Sodoma, hace alusión a Jr 26-36 (especialmente el Capítulo 29), para indicar que los discípulos de Jesús no se deben enredar en asuntos económicos y familiares en su "Babilonia" actual. Esta referencia subversiva a Jeremías genera preguntas hermenéuticas fascinantes sobre cuál texto bíblico (Jr 29 o Lc 17) se debe considerar normativa en el día de hoy. Para explorar esta pregunta, examiné dos crisis humanitarias actuales -el desplazamiento forzoso masivo en Colombia y la expulsión de migrantes indocumentados desde los Estados Unidos- para argumentar que ambas perspectivas bíblicas son pertinentes al siglo XXI, dependiendo del contexto.

Con el propósito de justificar este acercamiento, he argumentado que la diversidad y la historia redaccional de los documentos canónicos se pueden usar como modelos para una diferenciada interpretación política de las Escrituras para comunidades de fe hoy. Jeremías reconoció que las variadas ubicaciones geográficas y situaciones socioculturales de diferentes miembros del pueblo de Dios requerían exhortaciones morales que eran dramáticamente distintas, las cuales sin embargo representaban las palabras de Dios a esas comunidades. Lucas, de manera similar, reforma la tradición mateana a la luz del retraso de la parusía y conforme con sus agendas éticas, y subvierte la exhortación que Jeremías hizo a los exiliados judaítas, llamando a sus propios lectores a abandonar las actividades de plantar y edificar, en aras de asegurar sus vidas por medio de perderlas.

Así, a los diversos pueblos de Dios en el siglo XXI, que enfrentan distintas crisis de migración en contextos geográficos y políticos diversos y desde posiciones de poder opuestas, se puede decir alternativamente "plantar y edificar y buscar el bienestar de la ciudad" y "acordaos de la mujer de Lot. Todo el que procure preservar su vida, la perderá".

\section{Referencias}

Allen, Leslie C. Jeremiah. A Commentary. Louisville (KY): Westminster John Knox, 2008.

Amparo Camilo, Gloria. "Impacto psicológico del desplazamiento forzoso. Estrategia de intervención". En Efectos psicosociales y culturales del desplazamiento, editado por Martha Nubia Bello, Elena Martín Cardinal y Fernando Jiovani Arias, 27-40. Bogotá: Universidad Nacional de Colombia, 2000. 
Beale, G. K. Handbook of the New Testament Use of the Old Testament. Exegesis and Interpretation. Grand Rapids (MI): Baker Academic, 2012.

Beltrán, William Mauricio. "El voto evangélico, el nuevo botín electoral.” Diario El Tiempo, 17 de octubre 2017, https://www.eltiempo.com/politica/ partidos-politicos/analisis-de-la-influencia-del-movimiento-evangelico-en-lapolitica-colombiana-141382 (consultado el 4 de octubre de 2019).

Bock, Darrell L. Luke 9:51-24:53. Grand Rapids (MI): Baker, 1994.

Butcher, Kristin F. y Anne Morrison Piehl. "Crime, Corrections, and California: What Does Immigration Have to Do with It?” California Counts. Population Trends and Profiles 9/3 (2008): 1-23.

Cadavid Valencia, Laura Milena. "Elementos para comprender el desplazamiento forzado en Colombia. Un recorrido por normas, conceptos y experiencias". En Conversaciones teológicas del sur global americano. Violencia, desplazamiento y fe, editado por Oscar Garcia-Johnson y Milton Acosta, 3-26. Eugene (OR): Wipf and Stock, 2016.

Carroll, Robert T. Jeremiah. A Commentary. London: SCM, 1986.

Conzelmann, Hans. The Theology of St. Luke. Traducción de Geoffrey Buswell. London: Faber and Faber, 1960.

Cox, Daniel. "Growing Divide on Immigration and America’s Moral Leadership". Public Religion Research Institute, https://www.prri.org/research/growing-divideon-immigration-and-americas-moral-leadership (consultado el 2 de octubre de 2019).

Davidson, Steed Vernyl. Empire and Exile. A Postcolonial Reading of Jeremiah. London: Bloomsbury, 2013.

. "'Exoticizing the Otter'. The Curious Case of the Rechabites in Jeremiah 35”. En Prophecy and Power. Jeremiah in Feminist and Postcolonial Perspective, editado por Christl M. Maier y Carolyn J. Sharp, 189-207. London: Bloomsbury, 2013.

Duhm, D. Bernhard. Das Buch Jeremia. Kurzer Hand-Commentar zum Alten Testament. Tübingen: Mohr Siebeck, 1901.

El Tiempo. "El voto cristiano, una cantera dispersa en las elecciones." Diario El Tiempo, 28 de febrero 2018, https://www.eltiempo.com/elecciones-colombia-2018/ presidenciales/cristianos-para-las-elecciones-en-colombia-188412 (consultado el 4 de octubre de 2019). 
Emadi, Samuel. "Intertextuality in New Testament Scholarship. Significance, Criteria, and the Art of Intertextual Reading". Currents in Biblical Research 14/1 (2015): 8-23.

Evans, C. F. Saint Luke (2. ${ }^{a}$ ed.). London: SCM, 2008.

Fitzmyer, Joseph A. The Gospel According to Luke (X-XXIV). Introduction, Translation, and Notes. New York: Doubleday, 1985.

Goodacre, Mark. The Case Against Q. Harrisburg (PA): Trinity Press International, 2002.

. Goulder and the Gospels. An Examination of a New Paradigm. Sheffield (U. K.): Sheffield Academic, 1996.

Hays, Christopher M. "El discipulado de los laicos para el servicio integral en el mundo. Un experimento misiológico evangélico a favor de las personas en situación de desplazamiento en Colombia”. Albertus Magnus 10/1 (2019): 13-32.

- "Hating Wealth and Wives? An Examination of Discipleship Ethics in the Third Gospel”. Tyndale Bulletin 60/1 (2009): 47-68.

. "Introduction. Was Jesus Wrong about the Eschaton?" En When the Son of Man Didn't Come. A Constructive Proposal on the Delay of the Parousia, editado por C. M. Hays, 1-22. Minneapolis (MN): Fortress, 2016.

. "Justicia económica y la crisis del desplazamiento interno en Colombia". En Conversaciones teológicas del sur global americano. Violencia, desplazamiento y $f e$, editado por Milton Acosta y Oscar Garcia-Johnson, 44-64. Eugene (OR): Wipf and Stock, 2016.

. Luke's Wealth Ethics. A Study in Their Coherence and Character. Tübingen: Mohr Siebeck, 2010.

."Prophecy. A History of Failure?". En When the Son of Man Didn't Come. A Constructive Proposal on the Delay of the Parousia, editado por C. M. Hays, 23-38. Minneapolis (MN): Fortress, 2016.

. "The Delay of the Parousia. A Traditional and Historical-Critical Reading of Scripture. Part 1". En When the Son of Man Didn't Come. A Constructive Proposal on the Delay of the Parousia, editado por C. M. Hays, 79-107. Minneapolis (MN): Fortress, 2016.

. "The Delay of the Parousia. A Traditional and Historical-Critical Reading of Scripture. Part 2". En When the Son of Man Didn't Come. A Constructive Proposal 
on the Delay of the Parousia, editado por C. M. Hays, 79-107. Minneapolis (MN): Fortress, 2016.

Hays, Christopher M. y H. Leonardo Ramírez. La esperanza económica después del desplazamiento forzoso. Manual del facilitador. Medellín: Publicaciones SBC, 2018.

Hays, Christopher M. y Richard J. Ounsworth. "The Delay of the Parousia. A Traditional and Historical-Critical Reading of Scripture. Part 1". En When the Son of Man Didn't Come. A Constructive Proposal on the Delay of the Parousia, ed. C.M. Hays, 59-77. Minneapolis: Fortress, 2016.

Hays, Richard. Echoes of Scripture in the Letters of Paul. New Haven (CT): Yale University Press, 1989.

Heimburger, Robert W., David López Amaya, Guillermo Mejía Castillo, Fernando Abilio Mosquera Brand y Duberney Rojas Seguro. Iglesia, politica y desplazamiento. Cartilla para profesionales. Medellín: Publicaciones SBC, 2018.

Heimburger, Robert W., David López Amaya, Guillermo Mejía Castillo, Fernando Abilio Mosquera Brand, y Duberney Rojas Seguro. Iglesia, politica y desplazamiento. Currículo para personas en situación de desplazamiento. Medellín: Publicaciones SBC, 2018.

Horrell, David G. 1 Peter. London: T\&T Clark, 2008.

Ibánez, Ana María y Andrés Moya. "Do Conflicts Create Poverty Traps? Asset Losses and Recovery for Displaced Households in Colombia". En The Economics of Crime. Lessons for and from Latin America, editado por Rafael Di Tella, Sebastian Edwards y Ernesto Schargrodsky, 137-172. Chicago (IL): University of Chicago Press, 2010.

Ibáńez, Ana María y Carlos Eduardo Vélez. "Civil Conflict and Forced Migration. The Micro Determinants and Welfare Losses of Displacement and Colombia". World Development 36/4 (2008): 659-676.

Justapaz y Comisión de Paz del Consejo Evangélico de Colombia (Cedecol). Un llamado profético. Las iglesias colombianas documentan su sufrimiento y su esperanza. Informe 4. Bogotá: Justapaz, 2009.

Juza, Ryan P. "One of the Days of the Son of Man. A Reconsideration of Luke 17:22". Journal of Biblical Literature 135/3 (2016): 575-595.

Keown, Gerald L.; Pamela J. Scalise y Thomas G. Smothers. Jeremiah 26-52. Dallas (TX): Word, 1995. 
$\mathrm{Ku}$, Leighton, y Brian Bruen. "Poor Immigrants Use Public Benefits at a Lower Rate than Poor Native Born Citizens”. Economic Development Bulletin 17 (2013): 1-8.

Lang, T. J. “'You Will Desire to See and You Will Not See [It]'. Reading Luke 17:22 as Antanaclasis". Journal for the Study of the New Testament 33/3 (2011): 281-302.

Leuchter, Mark. Polemics of Exile in Jeremiah 26-45. Cambridge (U. K.): Cambridge University Press, 2008.

Lozano S., Arvey. "Reclamantes de tierras y líderes sociales: un asesinato por día." Las 2 Orillas, 9 de enero 2019, https://www.las2orillas.co/reclamantes-de-tierrasy-lideres-sociales-un-asesinato-por-dia (consutado el 4 de octubre de 2019).

Lundbom, Jack R. Jeremiah 21-36. A New Translation with Introduction and Commentary. New York (NY): Doubleday, 2004.

Martínez, Ramiro, y Matthew T. Lee. "On Immigration and Crime". The Nature of Crime 1/2 (2000): 485-524.

Mears, Daniel P. "Immigration and Crime: What's the Connection?" Federal Sentencing Reporter 14/5 (2002): 284-288.

Meek, Russell L. "Intertextuality, Inner-Biblical Exegesis, and Inner-Biblical Allusion. The Ethics of a Methodology". Biblica 95/2 (2014): 280-291.

Meng, Grace. "ICE Raids on US Immigrant Families Risk Serious Abuses". Human Rights Watch, 12 de julio de 2019, https://www.hrw.org/news/2019/07/12/ ice-raids-us-immigrant-families-risk-serious-abuses-0 (consultado el 11 de octubre de 2019).

Metzger, Bruce M. “The Fourth Book of Ezra”. En The Old Testament Pseudepigrapha. Volume 1. Apocalyptic Literature and Testaments, editado por James $\mathrm{H}$. Charlesworth, 519-559. New York (NY): Doubleday, 1983.

Nowrasteh, Alex. "By the Numbers: Do Immigrants Cause Crime?" Foundation for Economic Education, https://fee.org/articles/by-the-numbers-do-immigrants-cause-crime (consultado el 2 de octubre de 2019).

. "The 14 Most Common Arguments against Immigration and Why They're Wrong”. Cato Institute, https://www.cato.org/blog/14-most-commonarguments-against-immigration-why-theyre-wrong (consultado el 2 de octubre de 2019). 
O'Connor, Kathleen. "Jeremiah”. En The Oxford Bible Commentary, editado por John Barton y John Muddiman, 487-528. Oxford (U. K.): Oxford University Press, 2001.

Philips, Amber. “'They're Rapists.' President Trump's Campaign Launch Speech Two Years Later, Annotated". Diario Washington Post, 16 de junio de 2017, https:/www.washingtonpost.com/news/the-fix/wp/2017/06/16/ theyre-rapists-presidents-trump-campaign-launch-speech-two-years-laterannotated/?noredirect $=$ on\&utm term $=.2 \mathrm{~d} 8171064 \mathrm{aal} 1$.

Porter, Stanley E. "Allusions and Echoes". En As It is Written. Studying Paul's Use of Scripture, editado por Stanley E. Porter y Christopher D. Stanley, 29-40. Atlanta (GA): Society of Biblical Literature, 2008.

Quezada Plata, William Elvis, y Jhon Janer Vega Rincón. "Religión, conflicto armado colombiano y resistencia. Un análisis bibliográfico”. Anuario de historia regional $y$ de las fronteras 22/2 (2015): 125-55.

Red Nacional de Información. "Registro Único de Víctimas". https://rni.unidadvictimas.gov.co/RUV (consultado el 27 de febrero de 2020).

Rindge, Matthew S. "Illustrating Wisdom. Luke 12:16-21 and the Interplay of Death and Possessions in Sapiential Literature". Ph.D. Thesis, Emory University, Atlanta, 2008.

Rojas-Flores, Lisseth. "Desplazamiento de centroamericanos y colombianos. Violencia, trauma y el ministerio de la Iglesia”. En Conversaciones teológicas del sur global americano. Violencia, desplazamiento y fe, editado por Oscar Garcia-Johnson y Milton Acosta, 27-43. Eugene (OR): Wipf and Stock, 2016.

Rudolph, Wilhelm. Jeremia. Handbuch zum Alten Testament. Tübingen: Mohr Siebeck, 1947.

Schreiner, Josef. Jeremia II. 25,15 - 52,34. Würzburg: Echter Würzburg, 1984.

Sharp, Carolyn J. Prophecy and Ideology in Jeremiah. Struggles for Authority in Deutero-Jeremianic Prose. London: T\&T Clark, 2003.

Shaw, David A. "Converted Imaginations? The Reception of Richard Hays's Intertextual Method". Currents in Biblical Research 11/2 (2013): 234-245.

Strine, Casey A. "Embracing Asylum Seekers and Refugees. Jeremiah 29 as Foundation for a Christian Theology of Migration and Integration". Political Theology 19/6 (2018): 478-496. 
Thompson, J. A. The Book of Jeremiah. Grand Rapids (MI): Eerdmans Publishing Co., 1980.

Unidad de Restitución de Tierras. "Estadísticas de restitución de tierras". Unidad de Restitución de Tierras, https://www.restituciondetierras.gov.co/estadisticasde-restitucion-de-tierras (consultado el 4 de octubre de 2019).

Verhey, Allen. The Great Reversal. Ethics and the New Testament. Grand Rapids (MI): Eerdmans Publishing Co., 1984.

Volz, D. Paul. Der Prophet Jeremia. Kommentar zum Alten Testament. Leipzig: A. Deichertsche Verlagsbuchhandlung, 1922.

Weiser, Artur. Das Buch des Propheten Jeremia (4. ${ }^{a}$ ed.). Göttingen: Vandenhoeck und Ruprecht, 1960.

White House. "Remarks by President Trump at a California Sanctuary State Roundtable". White House, https://www.whitehouse.gov/briefings-statements/ remarks-president-trump-california-sanctuary-state-roundtable (consultado el 2 de octubre de 2019).

Wright, N. T. The New Testament and the People of God. London: SPCK, 1992.

York, John O. "The Last Shall be First. The Rhetoric of Reversal in Luke". Sheffield: JSOT Press, 1991.

Zallman, Leah; Steffie Woolhandler; David Himmelstein; David Bor y Danny McCormick. "Immigrants Contributed An Estimated \$115.2 Billion More to the Medicare Trust Fund than They Took out in 2002-2009". Heath Affairs 32/6 (2013): 1153-1160. 